Шурыгин Ю.А. ${ }^{1}$

\title{
Проблемы и перспективы российских экспортеров - малых и средних предприятий
}

\section{Введение}

На сегодняшний день российские компании - представители несырьевых секторов экономики - недостаточно широко представлены на международных рынках за пределами стран СНГ.

Экспортеры - крупные компании ссылаются на отсутствие видимой поддержки со стороны государства, а также недостаточное лоббирование и продвижение их интересов на зарубежных рынках. Отечественные же малые и средние предприятия (МСП) озабочены вопросами сохранения кадрового потенциала компаний, а иногда и банального выживания. Выход на внешние рынки для таких компаний влечет большое количество различных проблем: логистика и таможенное оформление, получение международных сертификатов, поиск и проверка потенциальных внешнеторговых партнеров, локализация продукции и товаров с учетом предпочтений местных заказчиков и др. Также предприятия не всегда могут справиться с возникающими экспортными проблемами. Очень часто российские МСП, не отказываясь от начала экспортных поставок совсем, откладывают реализацию практических шагов в данном направлении «на потом», находя для себя оправдание в избитой фразе «Нас там не ждут. Рынок давно поделен».

Аргументы крупного бизнеса логичны и понятны. Действительно, поддержка государства или ее отсутствие играют определяющую роль, особенно при участии в международных тендерах на реализацию различных инфраструктурных проектов. Позиция же МСП, на наш взгляд, неоправданна, поскольку не только оборачивается упущенным временем, но и играет на руку зарубежным конкурентам.

Иностранные МСП в отличие от российских коллег занимают заметно более активную позицию во внешней торговле. В некоторых странах на долю

1 Шурьгин Юрий Анатольевич - генеральный директор компании Dе la Ray Comsulting Ltd.; руководитель проекта Единого инбормачионного портала «Экпортерь России». 
экспортеров-МСП приходится свыше 40\% общего объема национального экспорта. В России же доля представителей малого и среднего бизнеса едва дотягивает до 0,3\% (табл. 1).

\section{Таблица 1}

Доля малых и средних предприятий в экспорте разных стран

\begin{tabular}{|c|c|c|c|}
\hline Страна & Доля МСП в экспорте, \% & Источник (организация) & Год \\
\hline Россия & 0,3 & Исследование МСП-Банка & 2014 \\
\hline Китай & 60 & $\begin{array}{l}\text { Издательство Университета } \\
\text { Цинхуа }\end{array}$ & 2009 \\
\hline Канада & 40 & $\begin{array}{l}\text { Министерство промышленности } \\
\text { Канады }\end{array}$ & 2011 \\
\hline Тайвань & 14 & $\begin{array}{l}\text { Министерство экономических } \\
\text { дел/Департамент МСП Тайваня }\end{array}$ & 2014 \\
\hline США & 33 & Министерство торговли США & 2012 \\
\hline Италия & 49 & EUROSTAT & 2011 \\
\hline Франция & 33 & То же & 2011 \\
\hline Испания & 44 & $-“-$ & 2011 \\
\hline Германия & 28 & $-“-$ & 2011 \\
\hline Великобритания & 27 & $-“-$ & 2011 \\
\hline Польша & 27 & $-“-$ & 2011 \\
\hline Швеция & 26 & $-“-$ & 2011 \\
\hline Нидерланды & 41 & $-“-$ & 2010 \\
\hline Португалия & 47 & $-“-$ & 2011 \\
\hline Австрия & 35 & $-“-$ & 2011 \\
\hline Дания & 35 & $-“-$ & 2011 \\
\hline Бельгия & 34 & $-“-$ & 2011 \\
\hline Чехия & 22 & $-“-$ & 2011 \\
\hline Словения & 38 & $-"-$ & 2011 \\
\hline Литва & 39 & $-"-$ & 2011 \\
\hline Венгрия & 17 & $-“-$ & 2011 \\
\hline Греция & 37 & $-“-$ & 2011 \\
\hline Финляндия & 24 & $-“-$ & 2011 \\
\hline Болгария & 23 & $-"-$ & 2011 \\
\hline Румыния & 36 & $-“-$ & 2011 \\
\hline Латвия & 53 & $-“-$ & 2011 \\
\hline
\end{tabular}


Таблица 1 (окончание)

\begin{tabular}{|l|l|l|l|}
\hline Страна & Доля МСП в экспорте, \% & Источник (организация) & Год \\
\hline Ирландия & 57 & $-“-$ & 2011 \\
\hline Словакия & 16 & $-{ }^{\prime}-$ & 2011 \\
\hline Эстония & 64 & $-“-$ & 2011 \\
\hline Кипр & 65 & $-{ }^{-}-$ & 2011 \\
\hline Люксембург & 12 & $-“-$ & 2011 \\
\hline Мальта & 49 & $-{ }^{-}-$ & 2011 \\
\hline Весь ЕС & 34 & $-“-$ & 2011 \\
\hline
\end{tabular}

Невольно возникает вопрос: а что у нас не так? Чтобы получить на него ответ и узнать о наиболее значимых факторах успешной работы на зарубежных рынках, необходимо проанализировать положительный опыт российских и зарубежных компаний по продвижению своей продукции и организации системы продаж.

\section{Стимул к экспорту}

Как правило, для руководителей российских предприятий экспортного направления основной сложностью является убедить собственника компании выделить ресурсы и начать заниматься экспортом. Сложность здесь связана с тем, что в отличие от работы в России работа на внешних рынках не дает быстрых финансовых результатов. В связи с этим приходится использовать различные нефинансовые аргументы: возможность привлечения в штат наиболее перспективных специалистов, престижность и хороший пиар для компании, изучение опыта и равнение на мировых лидеров в отрасли. Экспортная деятельность также создает хорошие возможности для начала эффективного диалога с представителями государственных структур, в задачу которых входит поддержка экспортеров-МСП.

Экспорт-менеджеры вынуждены находить формы и иногда по нескольку раз доносить свою аргументацию до руководства компаний. На практике же лучшим аргументом по-прежнему является потенциальная экспортная выручка. Ослабление рубля за последний год побудило многие компании начать всерьез рассматривать возможность поставок продукции на иностранные рынки.

\section{Первый блин - комом}

Зачастую причиной многих неудач отечественных компаний на зарубежных рынках является отсутствие системного подхода и целостной страте- 
гии. Достаточно часто можно встретить следующую ситуацию. Российский производитель, накопив достаточно ресурсов, принимает решение поучаствовать в какой-либо крупной международной выставке. Продукция компании вызывает значительный интерес у гостей выставки. Один из посетителей выставки - назовем его условно иностранный «Партнер» выражает неподдельный восторг уровнем технических решений и инженерной смекалкой российских специалистов. Сердца наших соотечественников наполняются заслуженной гордостью и надеждой на долгожданное признание. Сам же «Партнер» начинает пользоваться полным доверием руководства компании как надежный и адекватный отраслевой эксперт, сумевший профессиональным взглядом разглядеть и понять очевидные конкурентные преимущества российской продукции.

Уже во время выставки или сразу после ее окончания следует предложение «Партнера» оказать содействие с выводом российской продукции на местный рынок. Это предложение воспринимается как абсолютно логичный шаг, обусловленный совпадением интересов сторон: намерением российских производителей начать продажи и желанием «Партнера» заработать свой процент, продвигая продукцию россиян. В развитие сделанного предложения начинаются различные активные дейтвия: командировки, деловые встречи, переговоры с потенциальными покупателями, демонстрация образцов и т.д. Наши руководители строят большие планы и прорабатывают дальнейшие этапы сотрудничества...

А дальше что-то не складывается: иногда возникает неправильное понимание условий и формата сотрудничества, требований и рекомендаций «Партнера», иногда россиян плавно подводят к мысли, что их продукция не соответствует каким-либо требованиям и им пока преждевременно выходить на «серьезные» рынки. В некоторых случаях «Партнер» просто-напросто оказывается пустословом или просто проходимцем.

Итогом предварительного этапа сотрудничества может стать потеря веры в возможность успешно работать на иностранных рынках и перспективы реализации продукции предприятия. При этом никто особо не задумывается о том, откуда изначально взялся этот «Партнер», имелся ли у него опыт продаж отраслевой продукции и соответствовал ли он профессиональным критериям.

Поиск зарубежных внешнеторговых партнеров - одна из наиболее важнейших и ответственных задач. Практика показывает, что для достижения успеха отечественные компании должны руководствоваться жестким подходом к отбору потенциальных партеров. Основой успешных деловых отношений является профессионализм партнеров, которых необходимо искать целенаправленно и приступать к поэтапному развитию деловых отношений только после тщательного отбора и проверки потенциальных контрагентов. 


\section{Современные каналы продаж}

Местные внешнеторговые партнеры всегда смогут дать исчерпывающий ответ на вопрос о наиболее эффективных каналах продаж на интересующих россиян рынках. Активное развитие сети Интернет способствовало созданию целого ряда дополнительных возможностей попадания в поле зрения иностранных заказчиков. Международные базы данных (Kompass, Europages), виртуальные выставки (как специализированные, так и общепромышленные, например, Direct Industry), крупные торговые площадки (Alibaba, EC21), международные отраслевые порталы и электронные СМИ, контекстная реклама поисковых систем Яндекс, Google и Baidu, - вот далеко не полный современный инструментарий работы на зарубежных рынках. Отечественные производители зачастую относятся к таким каналам с большим недоверием и предпочитают обходить их стороной. Те же из экспортеров, которые принимают решение попробовать использовать современные возможности для попадания в поле зрения потенциальных заказчиков, нередко иногда делают ставку на один конкретный канал продаж. В некоторых случаях это приносит успех, но риск неэффективного вложения средств значительно возрастает.

Сегодня практически любой современный канал продаж можно с минимальными затратами испытать в тестовом режиме, чтобы понять и оценить, какое количество новых заказов/запросов он приносит. Большинство интернет-ресуров не берут плату за базовое размещение информации о компании и номенклатуре ее продукции.

Положительный опыт работы на внешних рынках показывает, что наиболее эффективным решением является регулярный мониторинг каналов и инструментов продаж, используемых компаниями-конкурентами, и применение полученной информации для построения гибкой системы продаж.

\section{Сервисные услуги}

Пожалуй, наиболее серьезной ошибкой российских промышленных производителей является недооценка сервисных услуг, привязанных к продукции предприятия. На международных промышленных рынках утвердилась модель, основанная на готовых решениях, которые могут предложить производители. Такие решения обычно включают модернизацию оборудования, обучение, гарантийное и постгарантийное обслуживание, регулярное обновление программного обеспечения. Готовые решения позволяют не только привязать заказчиков на среднесрочную перспективу и обеспечить необходимую стабильность и предсказуемость наличия заказов, но и снизить цену продукции, тем самым повысив ее конкурентоспособность. Еще одна причина, по которой сервисным услугам следует уделять особое внимание, заключается в том, что потенциальные клиенты из числа иностран- 
ных компаний изначально рассчитывают их услышать, поскольку привыкли к таким предложениям от конкурентов.

\section{Тонкости внешней торговли}

Практика работы на международных рынках имеет множество нюансов, о которых следует знать российским производителям.

Прежде всего это вопросы, связанные с организацией текущей работы экспорт-менеджеров. Для обеспечения нормального диалога с иностранными заказчиками необходимо иметь под рукой базовый набор, состоящий из нескольких шаблонов писем (как минимум - на английском языке), а также презентационных материалов, буклетов и datasheets - технических спецификаций продукции предприятия.

Разработке англоязычных версий технических спецификаций должно быть уделено достаточно времени и внимания, поскольку именно с изучения $d a-$ tasheets обычно и начинается знакомство с российской компанией. Лучший способ на практике произвести хорошее впечатление на зарубежного заказчика и избежать недоразумений - использование в качестве ориентиров аналогичных материалов ведущих зарубежных отраслевых производителей. Необходимо помнить, что при переводе материалов ни в коем случае нельзя «изобретать» термины и понятия, а следует пользоваться принятой в отрасли технической терминологией.

То же касается и руководств для пользователей. Как правило, российское руководство пользователя для высокотехнологичного оборудования составляется высококлассными специалистами-инженерами и рассчитано на коллег-инженеров. Практика зарубежных Manuals такова, что они построены по более или менее схожей схеме и рассчитаны на неспециалистов. Бессмысленно рассуждать и спорить о том, какой из подходов является более корректным и оправданным. На международных рынках так принято и точка. Руководство пользователя должно быть простым и четким, как у конкурентов.

Зачастую у производителя есть минимум времени, чтобы ответить на запрос от иностранной компании. Отправив запрос, потенциальный покупатель обычно рассчитывает получить ответ в течение одного, максимум двух дней. На практике же бывает крайне сложно правильно сходу рассчитать конечную стоимость груза и точные сроки поставок. Поэтому важно помнить, что ответ на запрос более чем через три дня практически гарантированно потеряет свою актуальность для потенциального заказчика. К сожалению, универсального совета здесь нет, и все же следует отметить, что лучше сразу вступить в диалог, указать стоимость товаров без учета таможенного оформления и расходов на логистику, чем молча приступать 
к детальным расчетам и выходить на связь с потенциальным покупателем через несколько недель.

Чтобы научиться правильно и быстро сортировать приходящие запросы на перспективные, сомнительные и спам, требуется некоторое время. Лучшее решение - это четкий алгоритм действий по проверке потенциальных контрагентов и набор стандартных ответов, адекватных запросам. Важность данного аспекта вдвойне актуальна с учетом того, что некоторые электронные торговые площадки грешат рассылкой автоматизированных запросов на цены от имени несуществующих компаний. Делается это специально с целью создания видимости большого числа заинтересованных покупателей и побуждения компании оформить платный пакет размещения данного ресурса.

Практика показывает, что отсутствие четких алгоритмов работы с запросами может в буквальном смысле парализовать работу экспортного отдела.

\section{Положительный образ компании}

Имеет смысл внимательно анализировать и использовать приемы зарубежных участников рынка в плане позиционирования предприятий и продукции на рынках интересующего региона. Недооценка важности создания правильного образа компании приводит и к недооценке значимости интернет-ресурсов отечественными производителями. Сегодня уже очень сложно привлечь, а в некоторых случаях и вовсе невозможно заинтересовать новых зарубежных заказчиков из числа крупных компаний, не имея качественного англоязычного сайта.

В случае, если российские компании не уделяют внимания позиционированию предприятия, им неизбежно придется мириться с тем фактом, что их продукция будет продаваться под чужими брендами.

\section{Заключение}

Несмотря на наличие большого числа сложностей и проблем, свыше трех тысяч отечественных производителей несырьевой продукции из числа МСП успешно работают на международных рынках.

Основными факторами успеха российских компаний являются:

- личность руководителя экспортного направления;

- наличие хорошего контакта с руководством компании;

- качество продукции и предлагаемых сервисных решений.

По сложившейся практике действующие российские экспортеры-МСП полагаются исключительно на свои собственные силы и средства. При расшире- 
нии поддержки со стороны государства существует реальная возможность многократного увеличения объемов экспорта российских МСП и значительного расширения географии поставок отечественной продукции.

Shurygin . $^{1}$

\section{Problems and prospects of SMEs exporters} in Russia

\section{Development of Russian export:}

\section{current model or a new one}

Issues related to development of export activities and export support measures in $\mathrm{RF}$ are analyzed with special emphasis on ways to increase number of exporting companies and improve export possibilities for SMB enterprises. Possible steps to improve export support mechanism in RF and make it easier to access for numbers of companies are discussed. Practices of other countries in these areas are analyzed. After the series of seminars in HSE: "Discussion of national export strategy. Export: using existing model or development of a new one”.

Key words: export, export promotion, $S M B$ enterprises, nonfinancial export support measures.

\section{Russian export: some problems and features}

1 Shurygin Yuri - general director De la Rey Consulting Ltd.; project Head National Web Portal "Russian Exporters". 